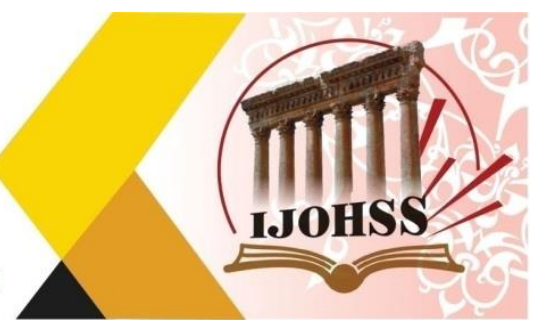

\title{
تجليات التناص الايني في كتاب أحضان الجبال للكاتبة هدى الحوسني
}

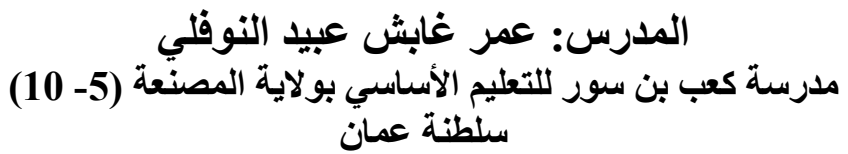 \\ البريد الإكتروني:
}

الملخص

يعد مصطلح التناص من المصطلحات النقدية المعاصرة التي تبوأت مكانـة عظيمة في النقد الأدبي الحديث و هي تقنيـة إجر ائيـة تمنح النص نسيجا مميز ا من الأصـوات الغائبـة، فالتنـاص يحمل مجموعـة من التصـور ات و الرؤى الجمالية القادرة في منح الأعمال الأدبية مزيدا من الاستمر ارية والدينامية الحية لاتصالها بالأبعاد الدالالية التي لها وزنها المعرفي في الذاكرة الجمعيـة. يحاول هذا البحث استجلاء المتناصـات الدينية ( القر آنيـ الحديث الثريف) و إبر از دور ها في إنتاج الدلالة. وقد اخترنا عينة تطبيقية لرصد التناصات الدينية في نتاج الكاتبـة هدى الحوسني من أجل إيضاح التجليات الإبداعية التي أسهمت في تشكيل النص تشكيلا جماليا، و الابتعاد عن القراءات السطحية إلى القر اءات المنطقية القابلة للتناول و الفهم و التنأويل بين القراء.

الكلمات المفتاحية: التناص، التناص التركيبي للقر آن الكريم، التناص مع الحديث الثريف. 


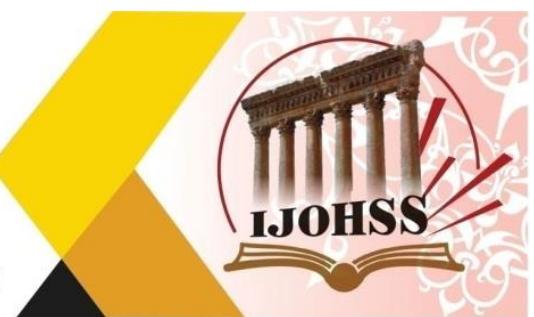

\title{
Clarification of Religious Intertextuality in the Book , "Embraces of Mountains," written by Huda Al Hosani
}

\author{
Teacher: Omar Ghabish Al Nofli \\ K'ab Bin Soor Basic Education School for Grades 5-10 \\ Oman \\ E-mail: omar841340@gmail.com
}

\begin{abstract}
Intertextuality is a modern critical term which has a great status in the modern literary criticism. It is an action technique which gives a text a mixture of old texts. Intertextuality includes a group of aesthetic images which give a literary work continuity and live productivity as they are related to meaningful dimensions which have a knowledgeable status in the cultural encyclopedia. This research tries to clarify religious intertextuality (Qur'an-Hadith) and how it produces meanings. We have chosen a practical sample to clarify religious intertextuality in Hoda Al Hosania's works to clarify creative factors which have contributed to an aesthetic formation of a literary text.
\end{abstract}

Keywords: Intertextuality, Compound intertextuality with the Holy Qur'an, Intertextuality with Hadeeth. 


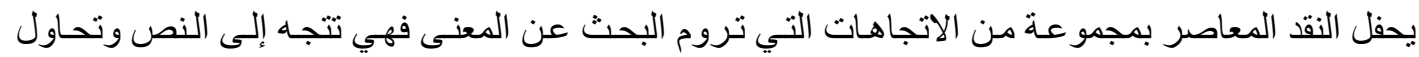

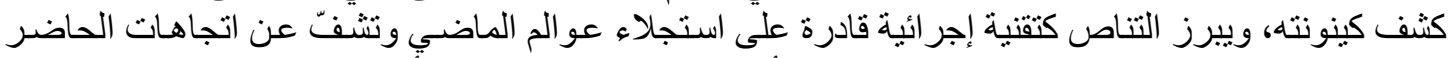

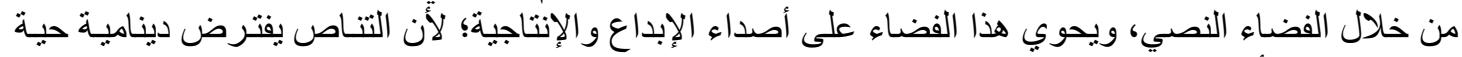

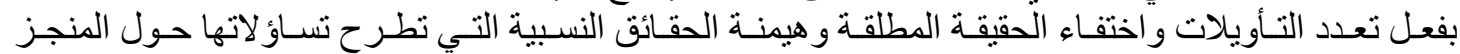

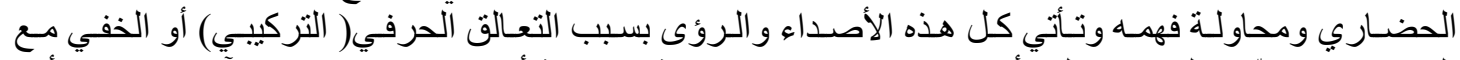

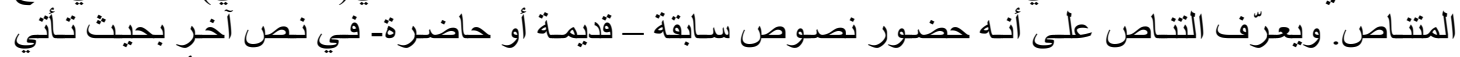

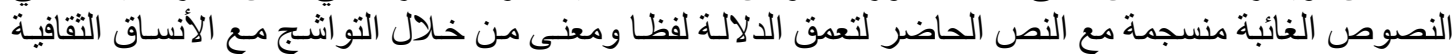

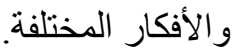

أسهمت نتاجات الكاتبة العمانية هدى سالم الحوسني في تشكيل المعنى الجمالي إذ اتسعت مضـامين أعمالها

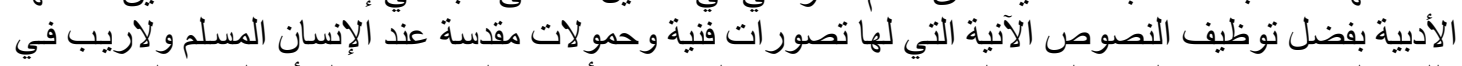

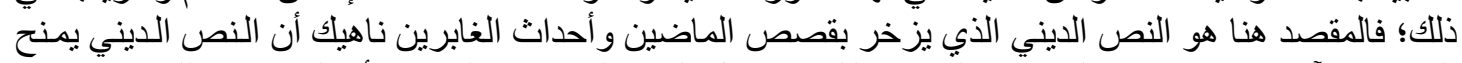

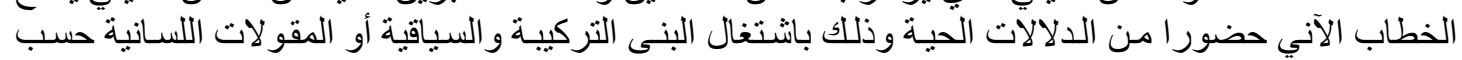

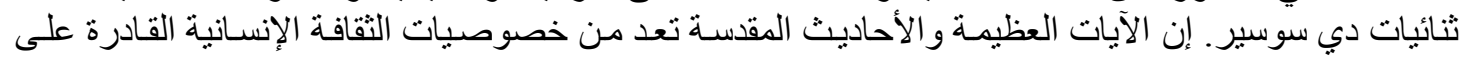

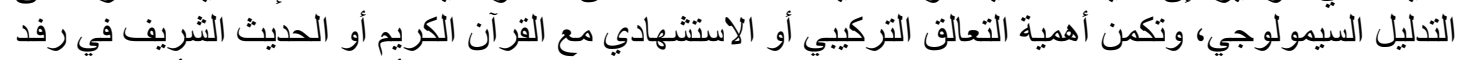

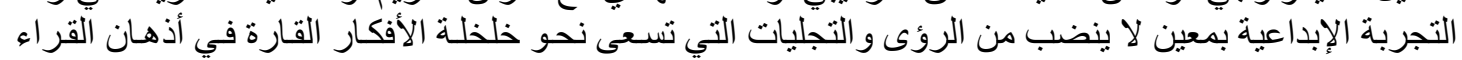

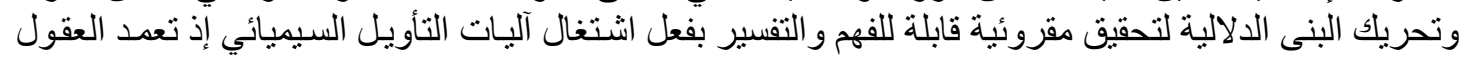

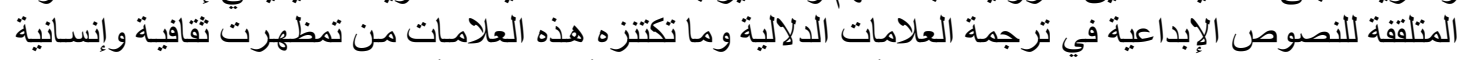

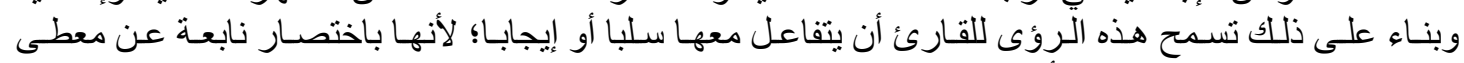
حضاري وتز اثي ضارب في في الأعماق.

ويظهر أن التشكيل الدلالي في تجربة الكاتبة هدى الحوسني يتجلى في المتناصـات الدينيـة التي حققت علامـة

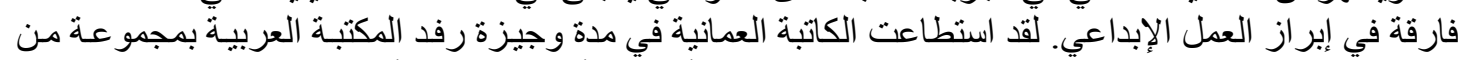

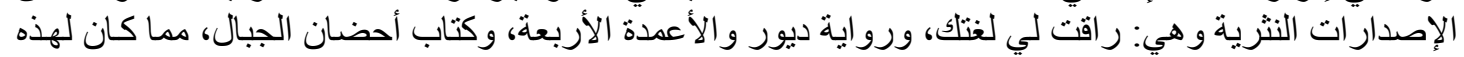

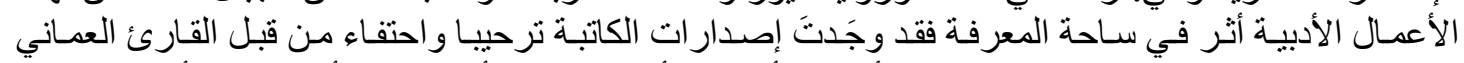

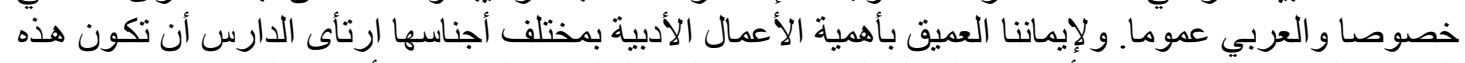

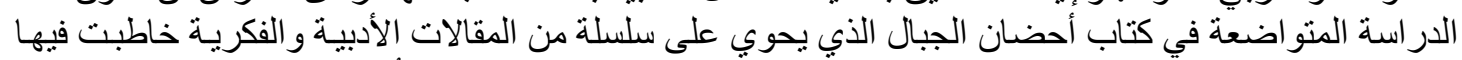

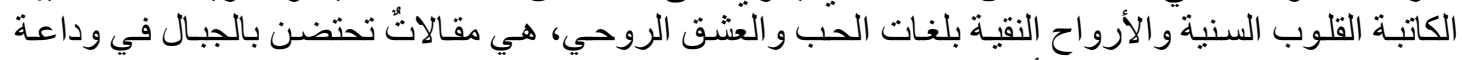

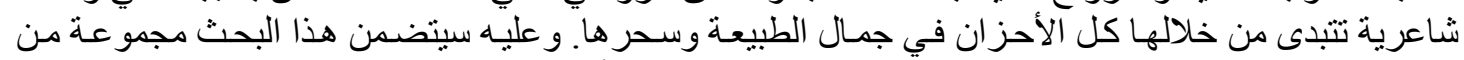

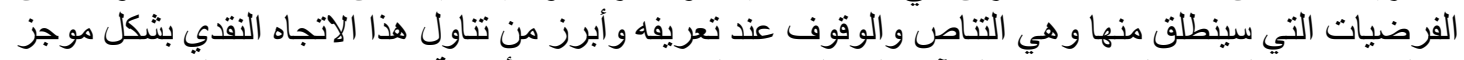

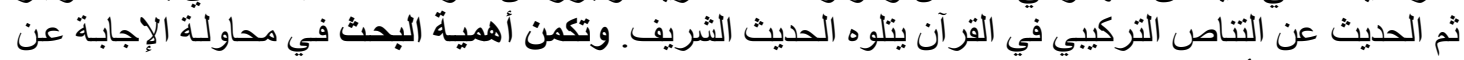

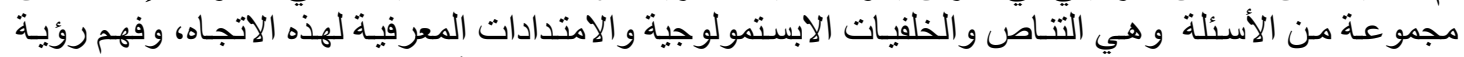

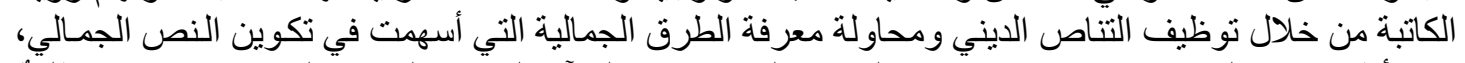

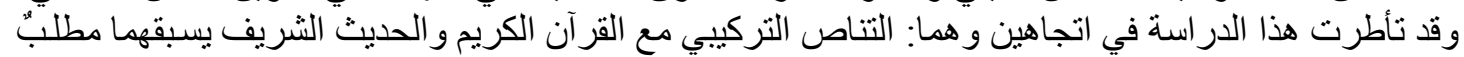

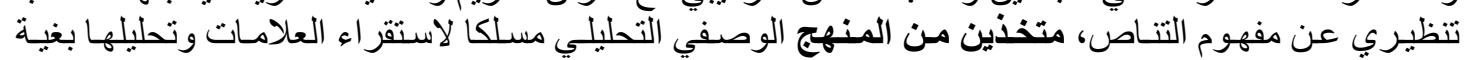

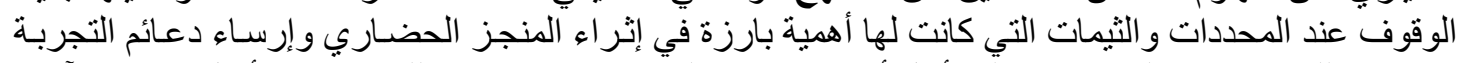

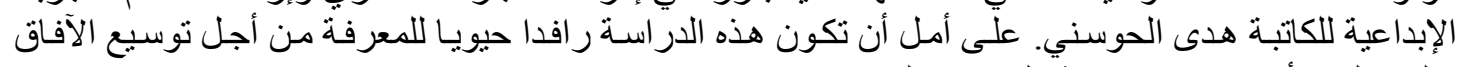
و المدارك، و أخير النرجة هذى من الله التوفيق والسى السداد. 
انبثق مصطلح التناص(intertextualite) في مرحلة الستينات من القرن الماضي وهو مصطلح اجترحته

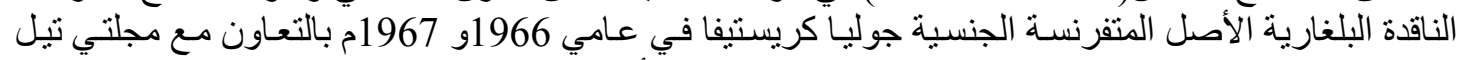

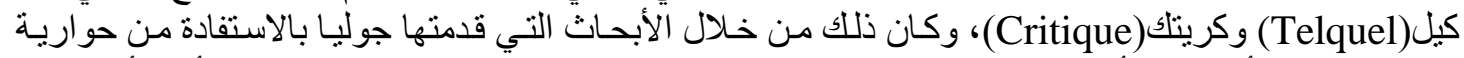

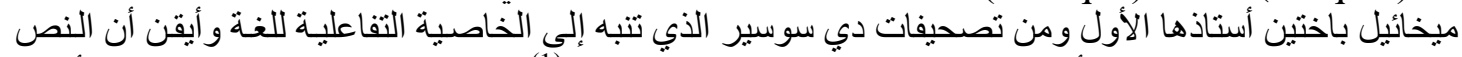

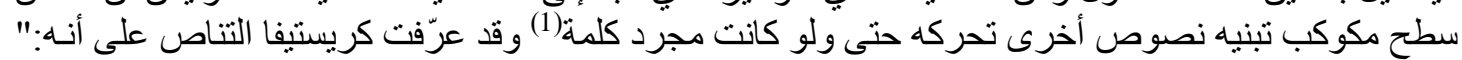

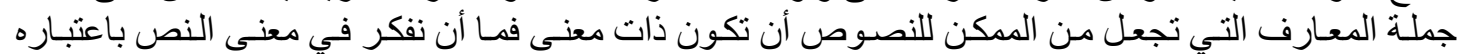

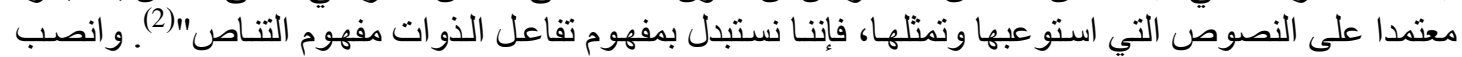

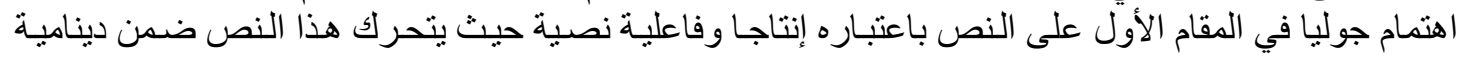

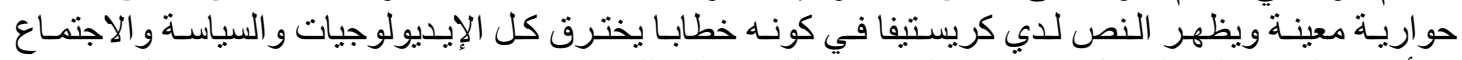

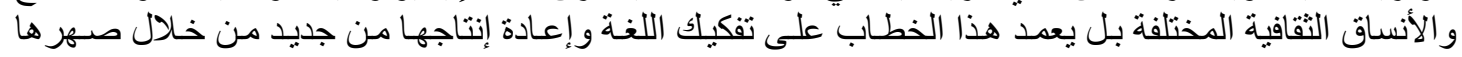

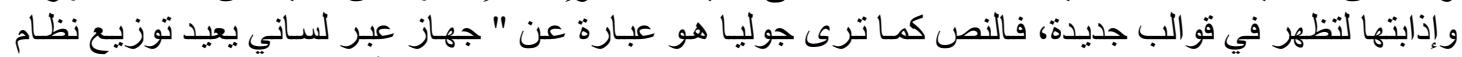

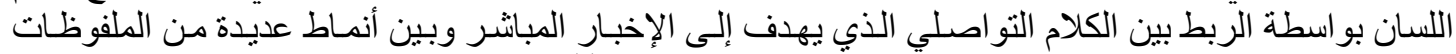

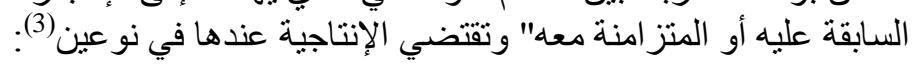

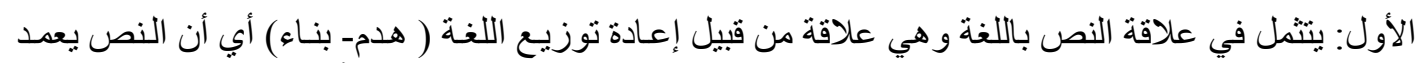

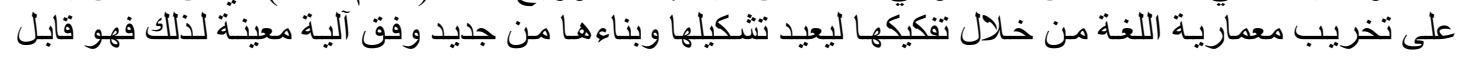
للتنتاول عبر المقولات المنطقية لا عبر المقولات لات اللسانية الخالصة.

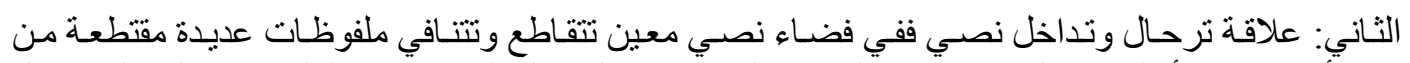

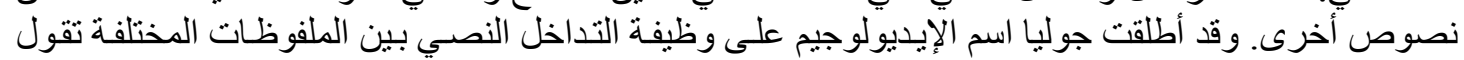

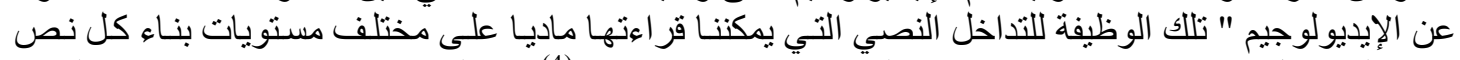

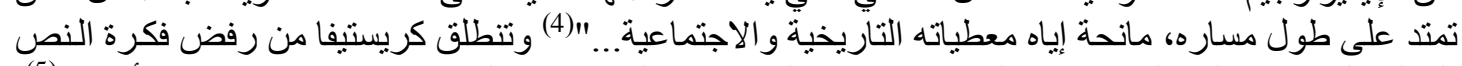

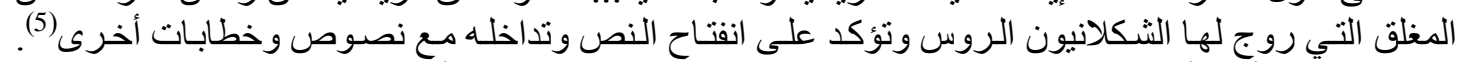

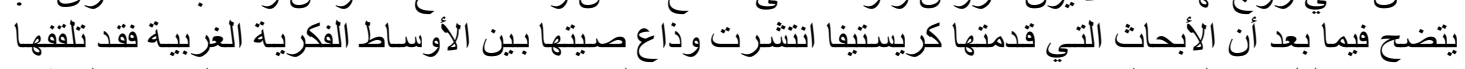

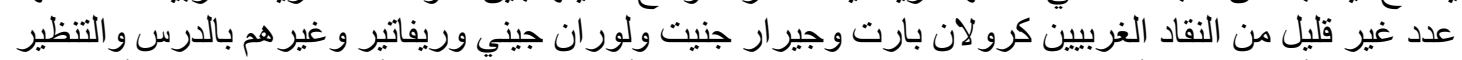

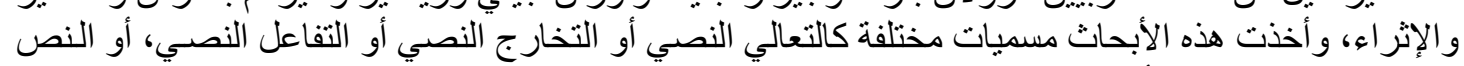

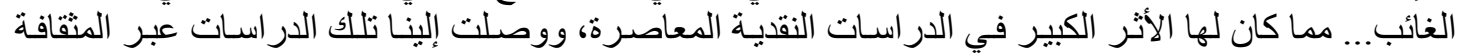

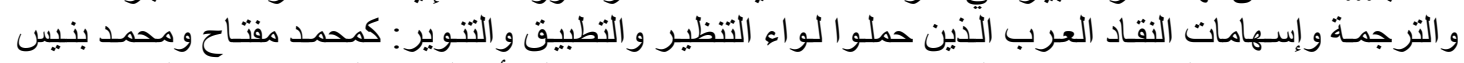

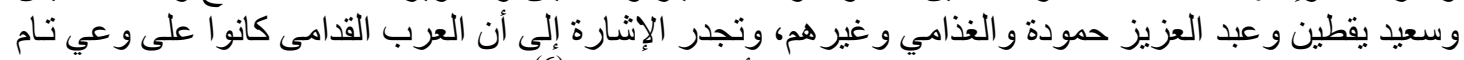

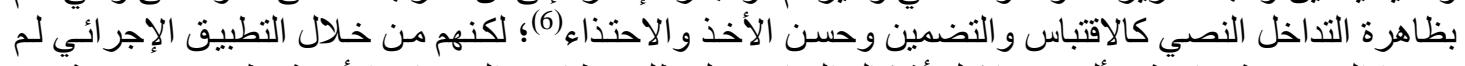

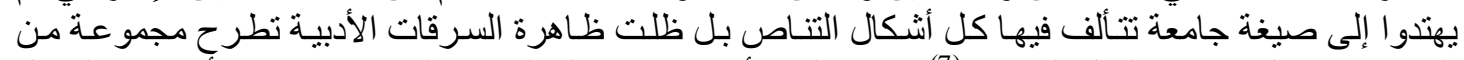

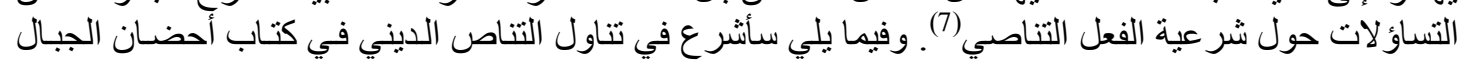

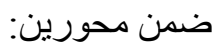

$$
\text { التناص مع الحديث الثربيف. القرآن الكريم. }
$$

\section{1- 1- التناص التركيبي مع القرآن الكريد:}

يعد القرآن الكريم المصدر الأول من مصسادر التشـريع الإسـلامي لدى المسلمين فهو معين قيم يزود الأدبـاء

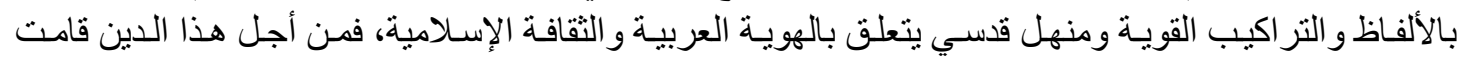

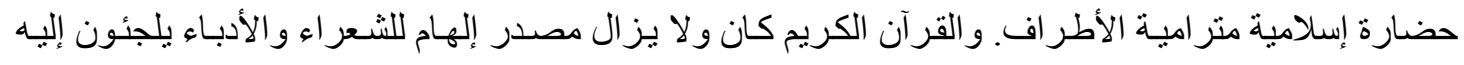


خلال تجاربهم الإبداعية يمتحون معانيه وينهلون أفكاره ورؤاه حيث يمنح النص القر آني قداسة روحية ذات رؤيـة

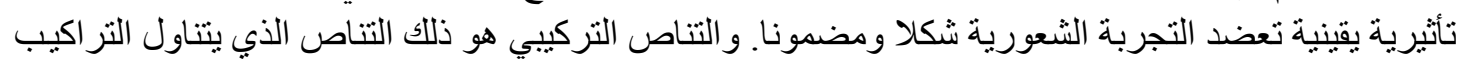

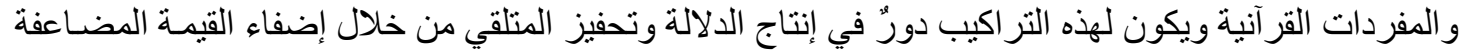

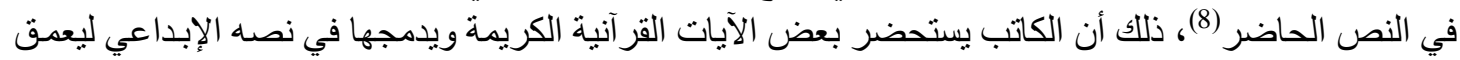

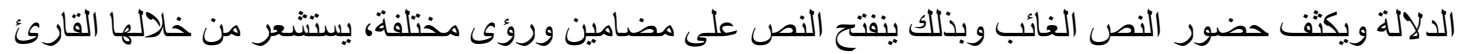

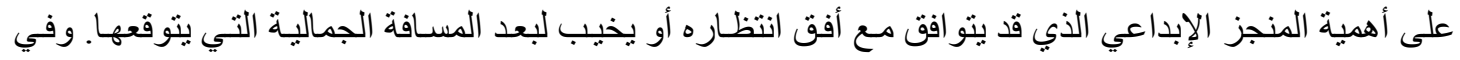

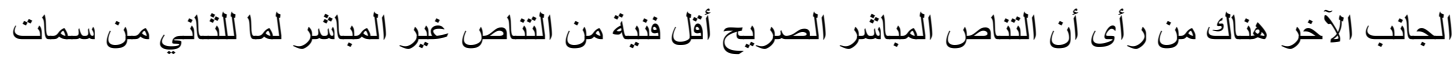

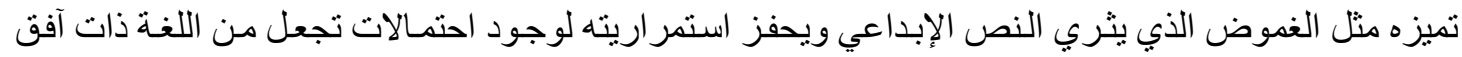

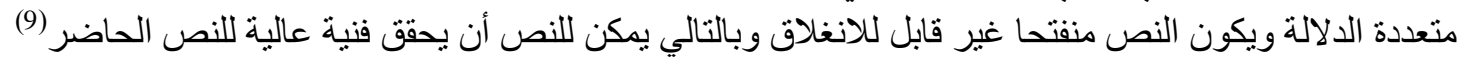

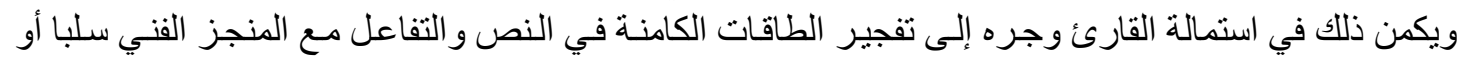
إيجابا ، ائتلافا أو اختلافا و هكذا.

وتجدر الإشارة أن هذا النوع من التناص الديني يندرج تحت مسمى التناص الخـارجي الذي يعني "تداخل

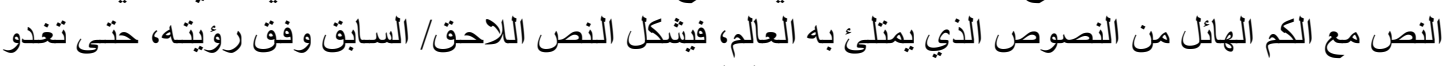

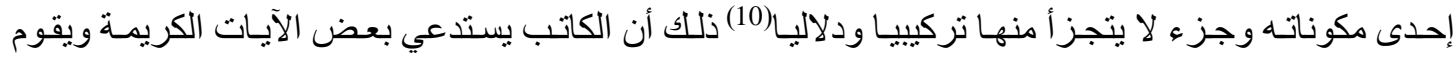
بإدماجها في النص الحالي هادفا من ور اء هذا التعالق النصي تكثيف الدالة النة وتعميق الرؤى المختلفة. استلهمت الكاتبة هدى تجربتها الإبداعية من القرآن الكريم فاسنطاعت بذلك أن تمنح النص دلالات أرحب نحو إنس

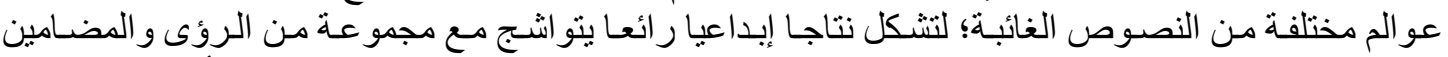

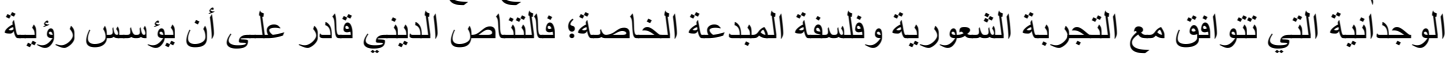

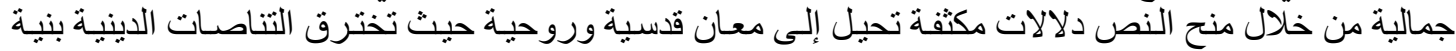

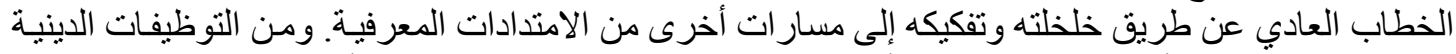

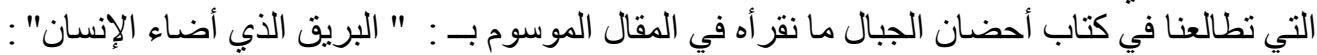

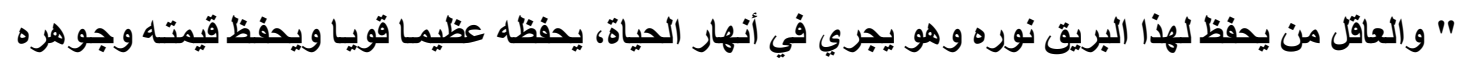

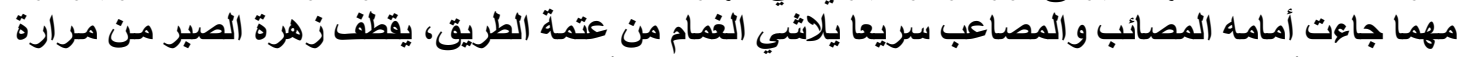

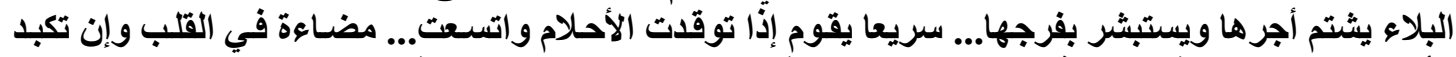

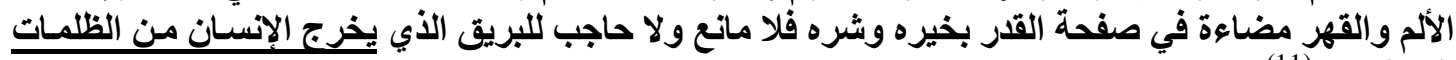

إلى النور" (11)

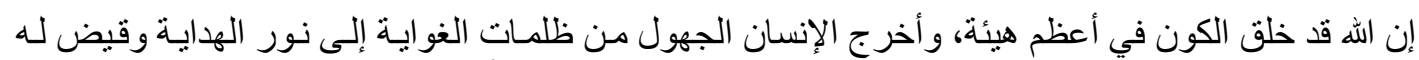

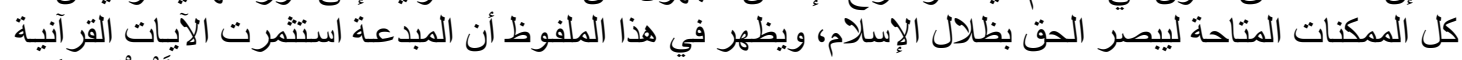

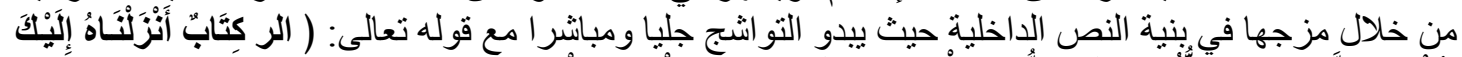

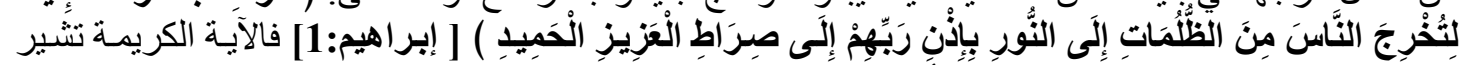

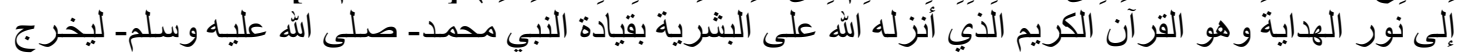

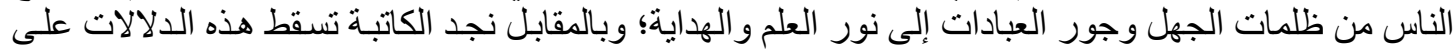

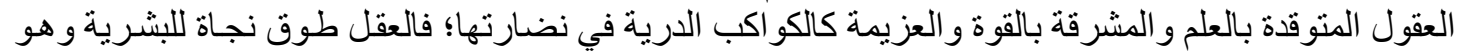

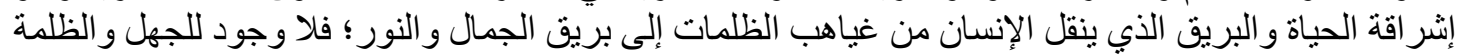

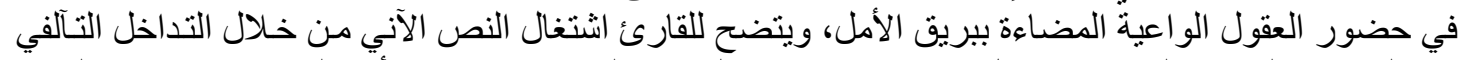

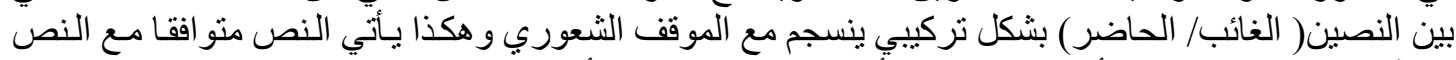

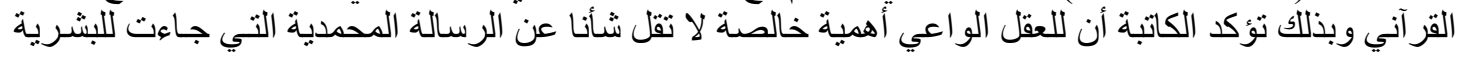


أجمعين حيث يمثل هذا الحضور الديني إثراء جماليا يعمل على انسجام النص وتعميقه. ونورد على ذلك مخططا

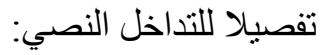

$$
\begin{aligned}
& \text { النور المبين ( القرآن الكريم) } \\
& \text { العقل الواعي } \\
& \text { الظلمات ( الغواية والانحراف عن طريق الحق) }
\end{aligned}
$$

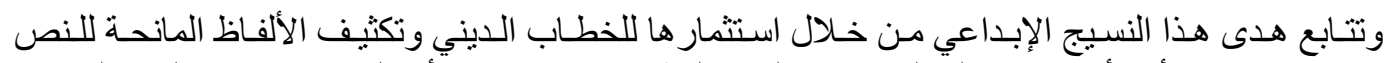

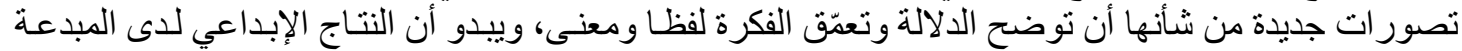

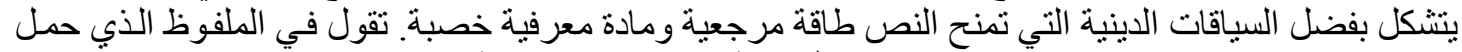

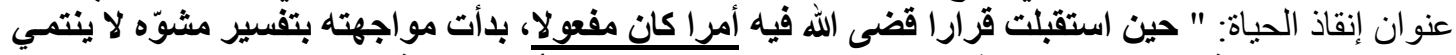

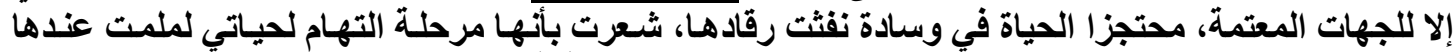

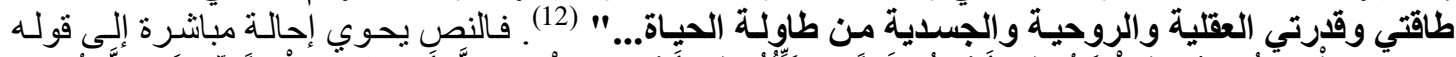

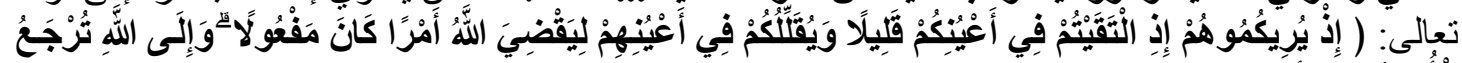

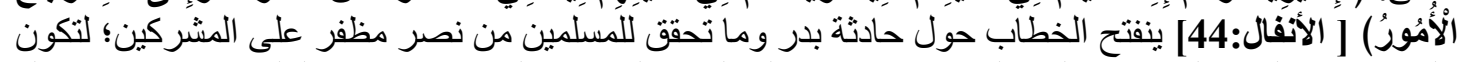

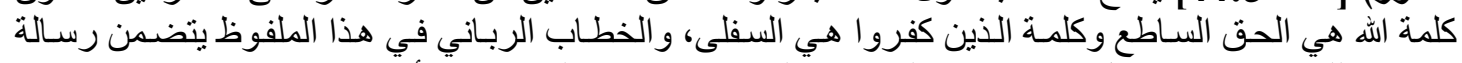

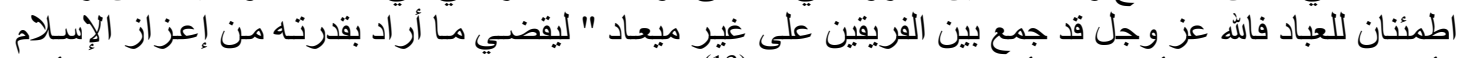

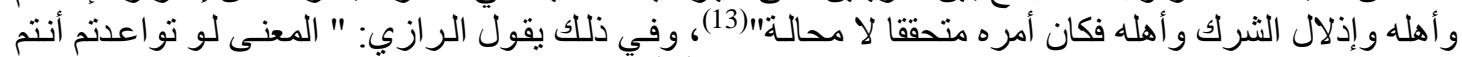

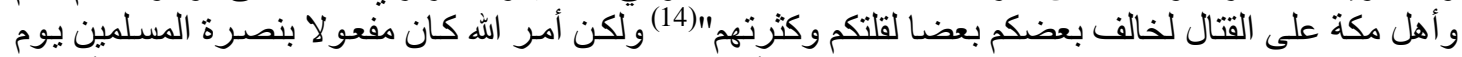

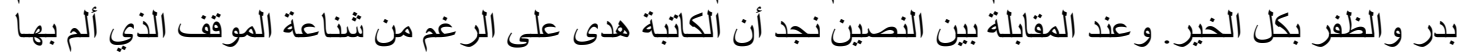

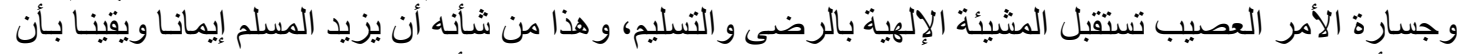

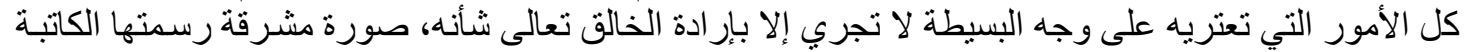

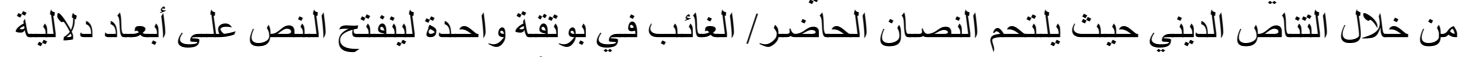

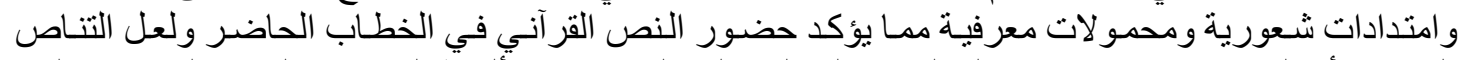

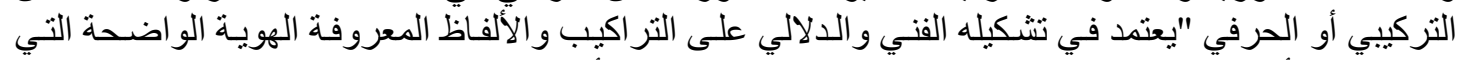

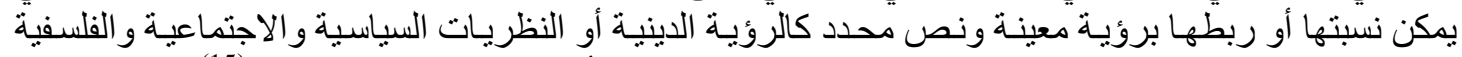

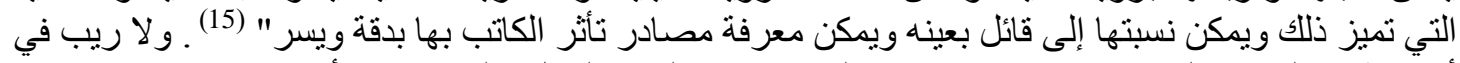

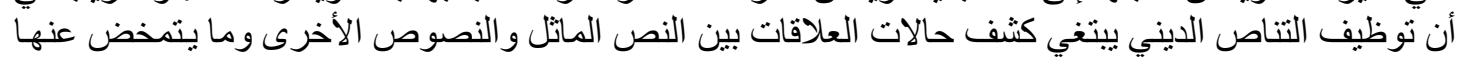

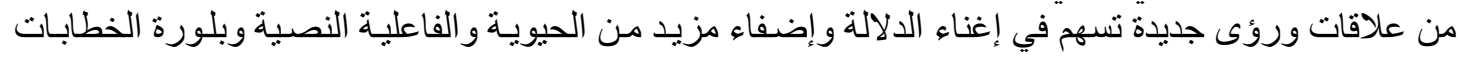
بشكل يتناسب مع تجربة المبدع.

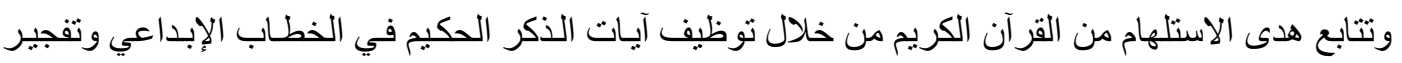

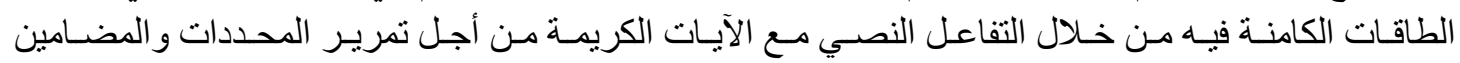

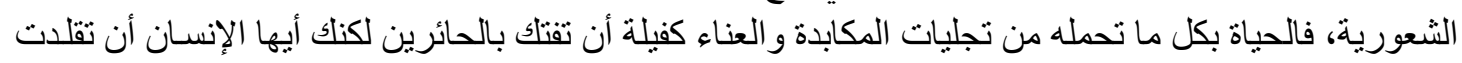

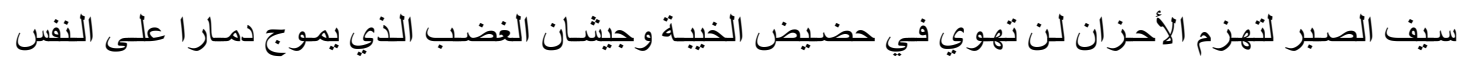

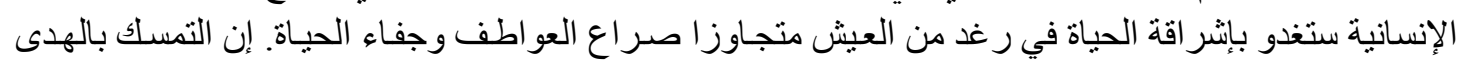

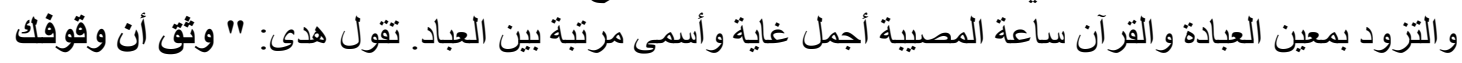

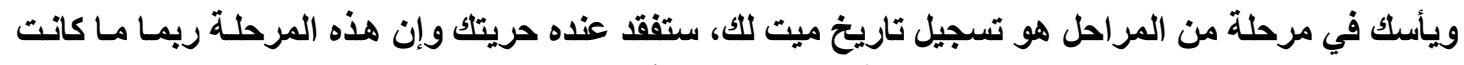

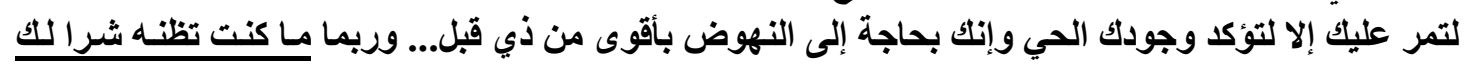

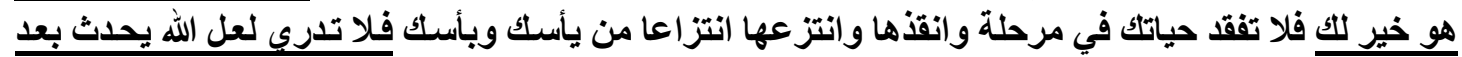

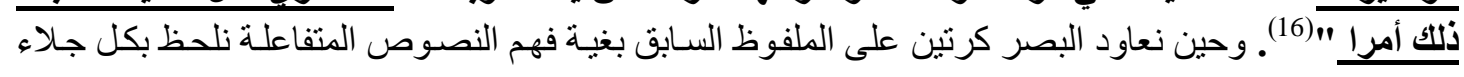




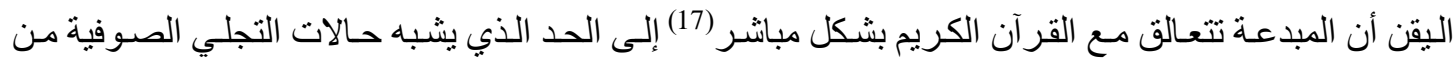

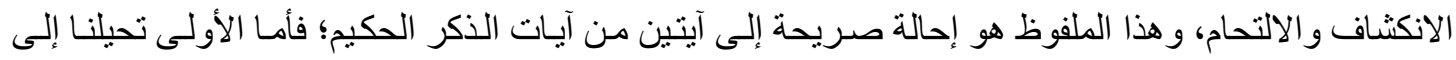

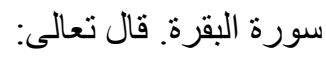

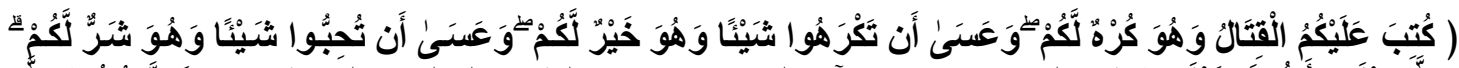

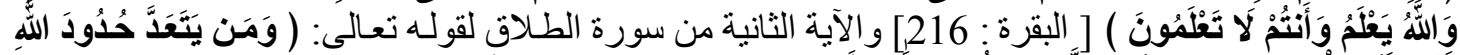

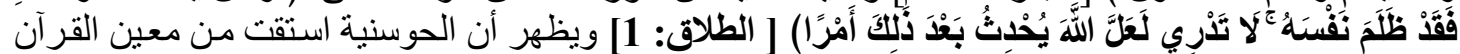

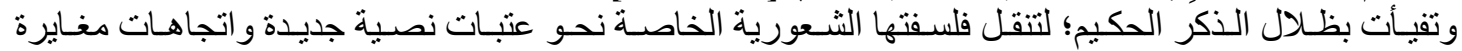

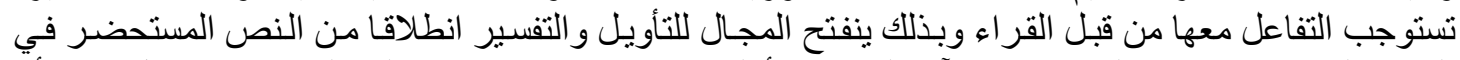

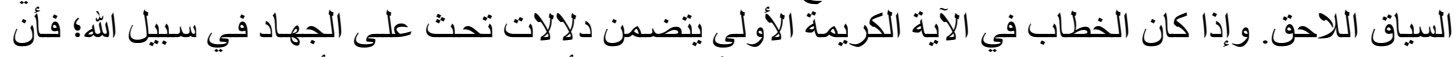

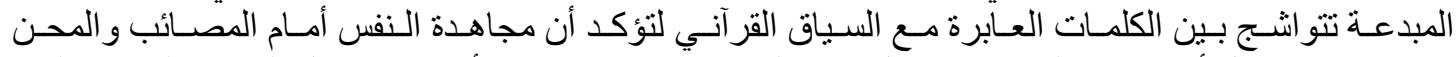

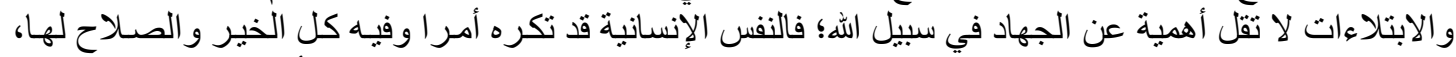

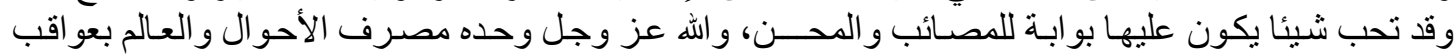

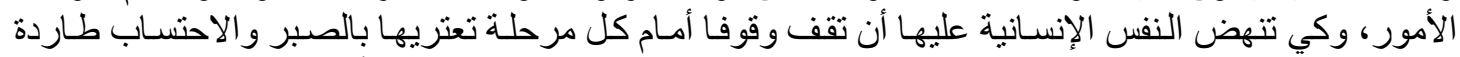

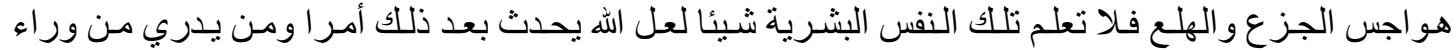
المصيبة لعلها تكون منحة ربانية وهبة عظيمة من رب ابل العباد.

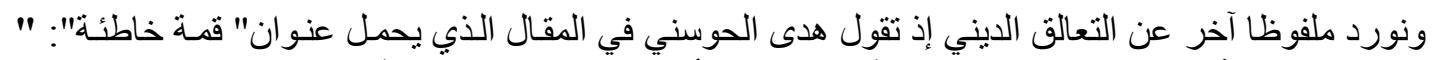

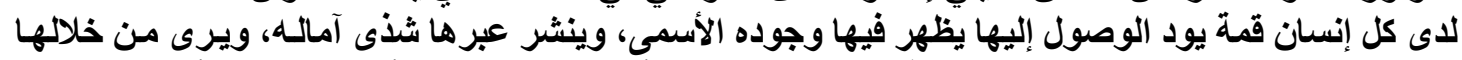

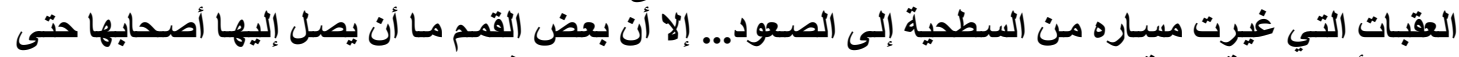

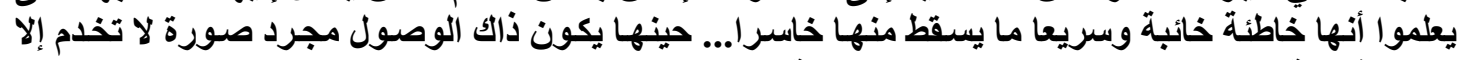

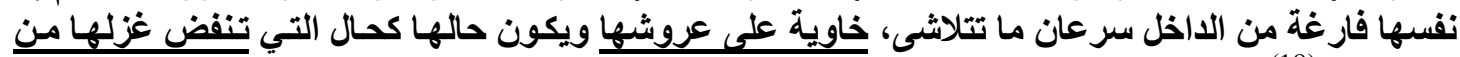

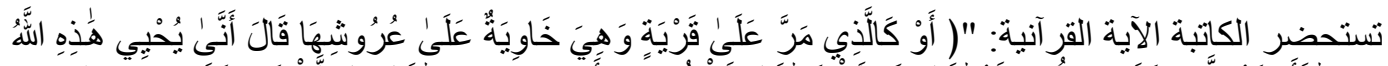

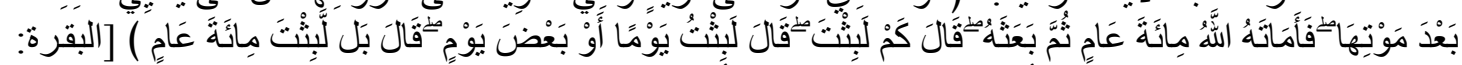

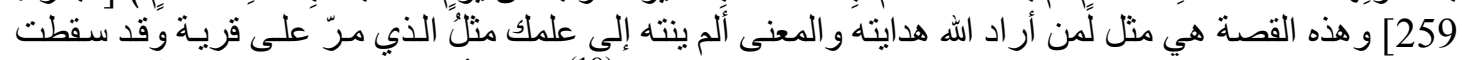

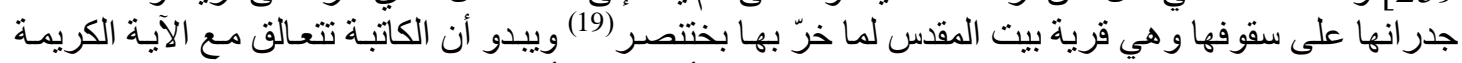

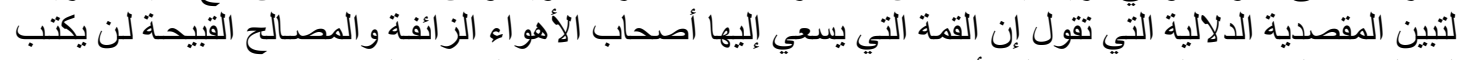

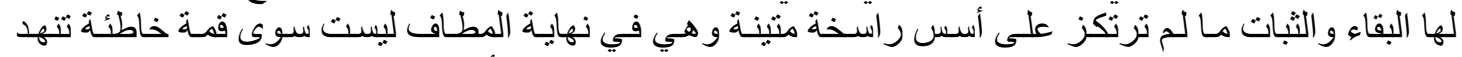

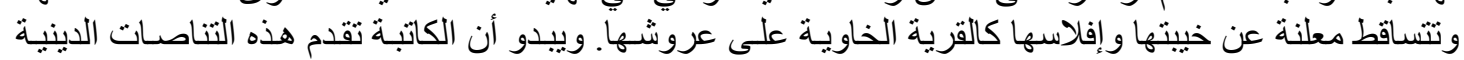

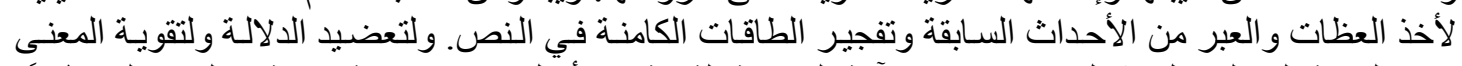

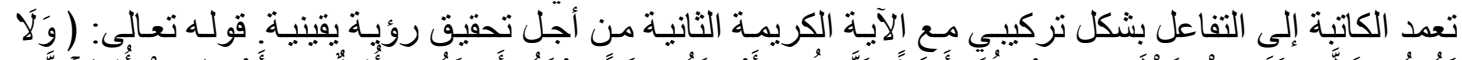

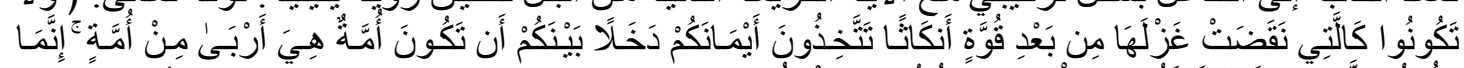

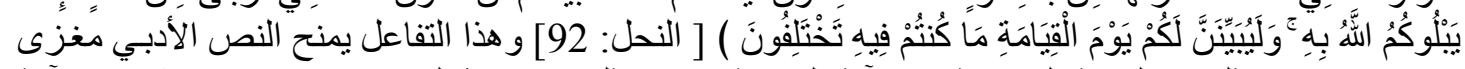

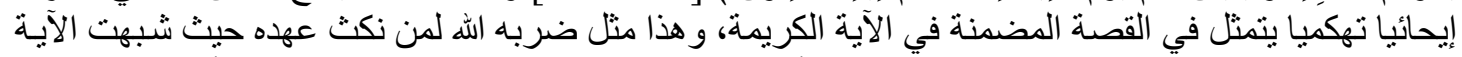

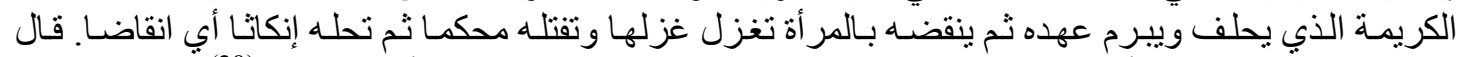

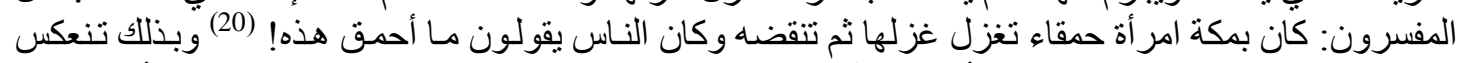

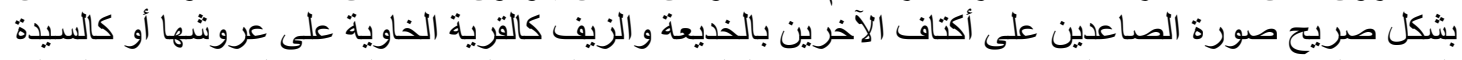

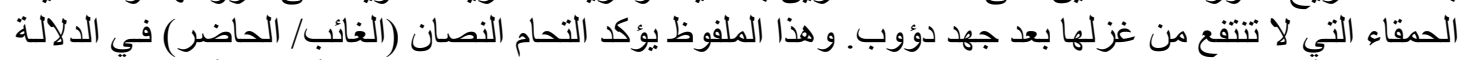

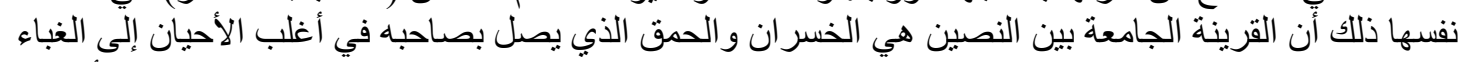

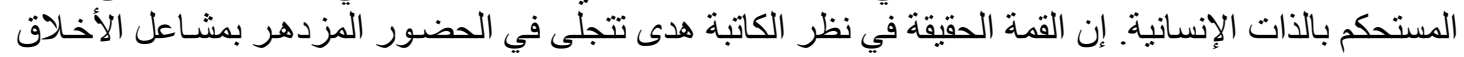
و النز اهة المقدة التي لا شريك لها وليس بالتزلف و النفاق الذي الذي يلقي بصأحبه في خريف الظلمات. 


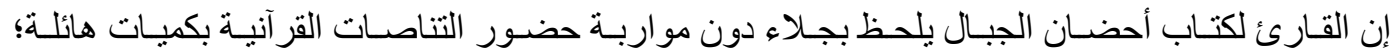

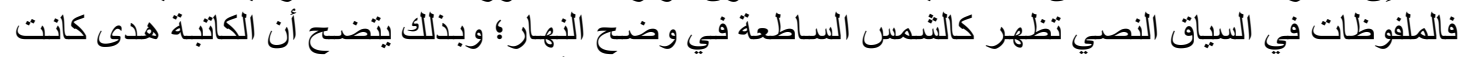

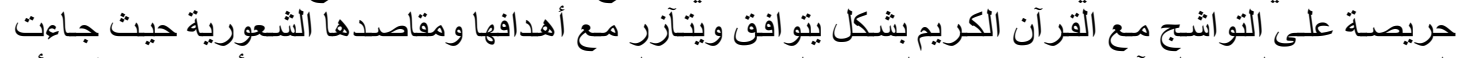

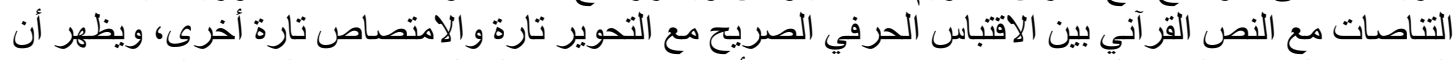

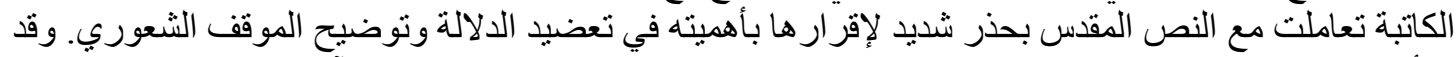

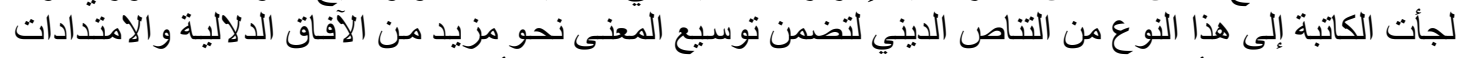

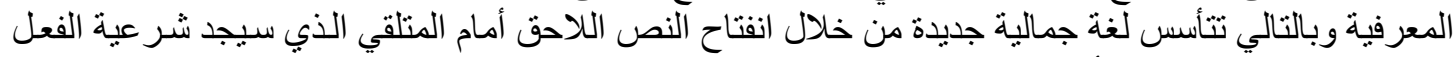

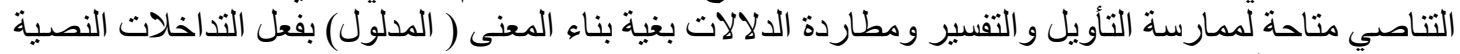
و الانزياحات الأسلو بية الموظفة في سياقات مختلفة.

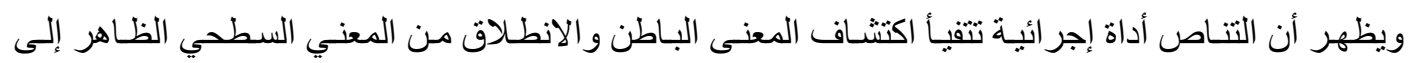

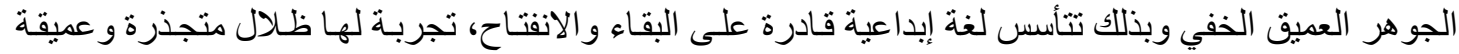

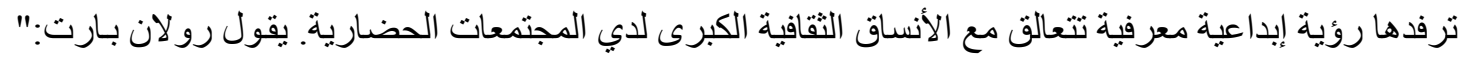

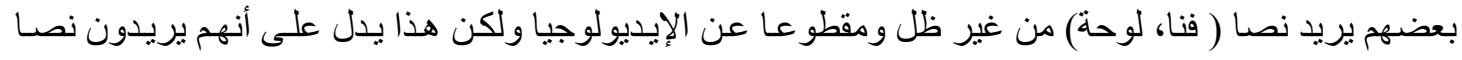

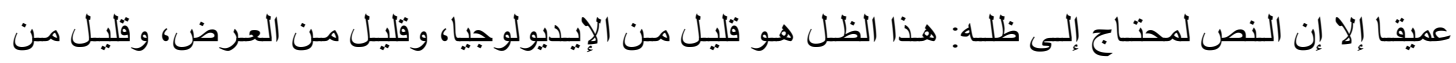

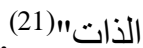

\section{2-1-1 التناص الديني مع الحديث الشريف:}

أما على صعيد الحديث النبوي الثريف والذي يأتي كمصدر ثان من مصادر التشريع الإسـلامي فنرى الكاتبـة

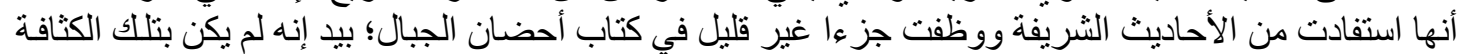

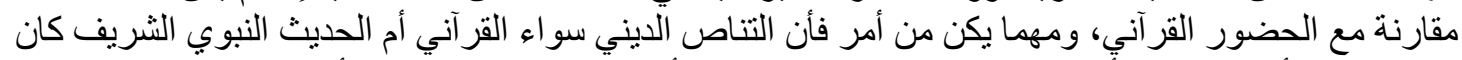

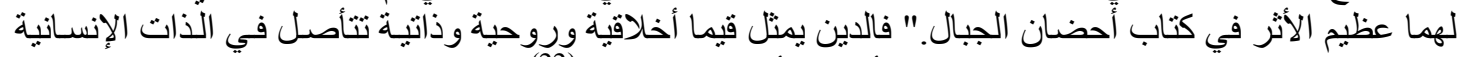

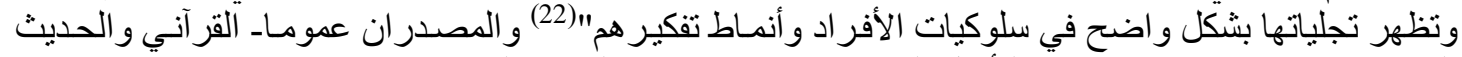

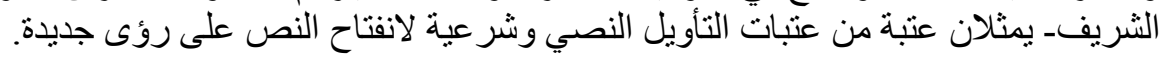

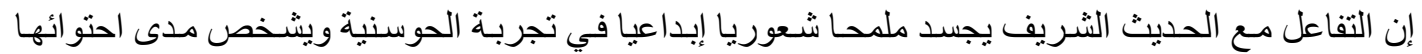

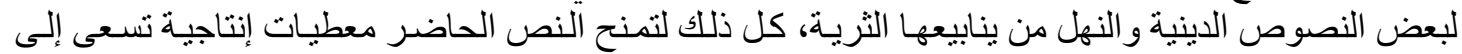

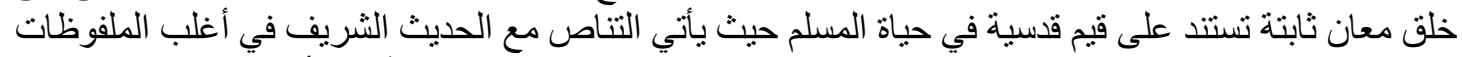

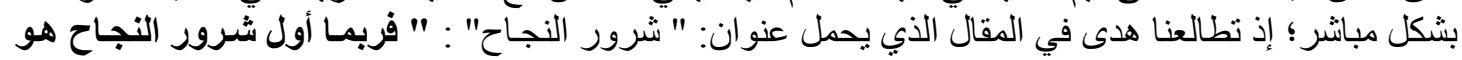

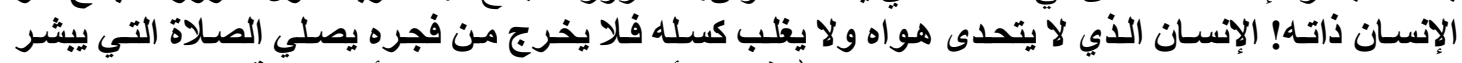

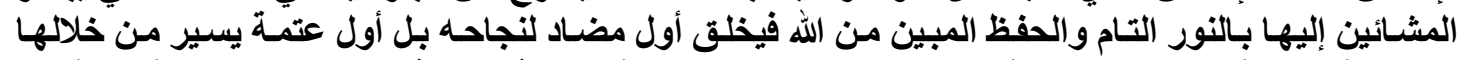

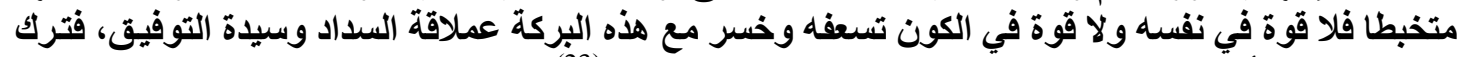

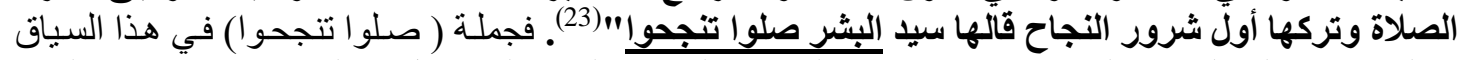

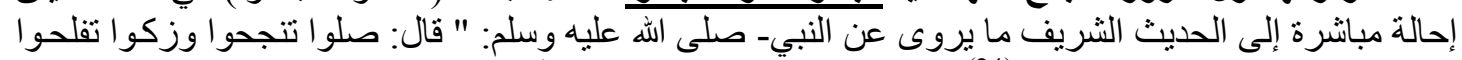

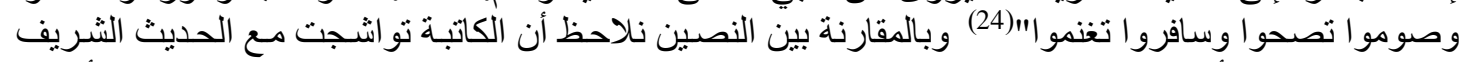

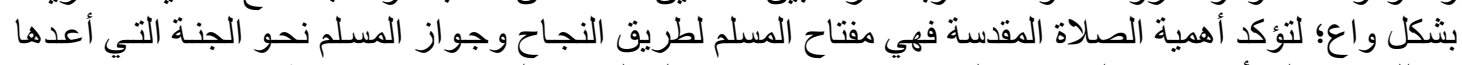

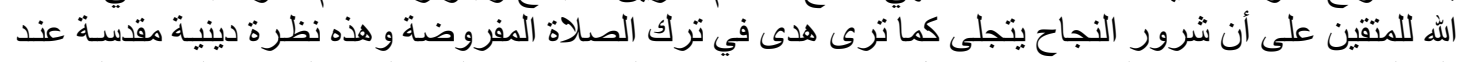

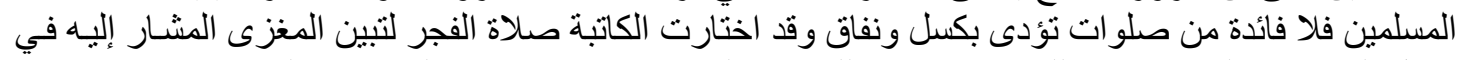

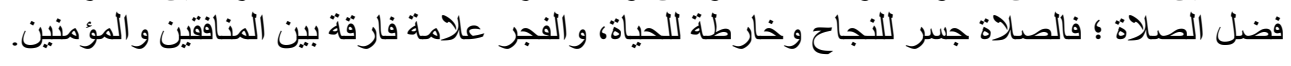

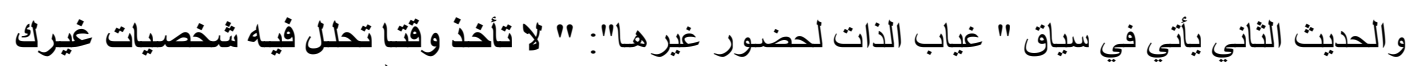

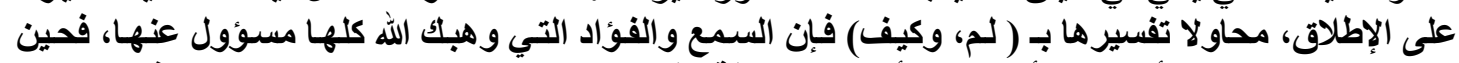

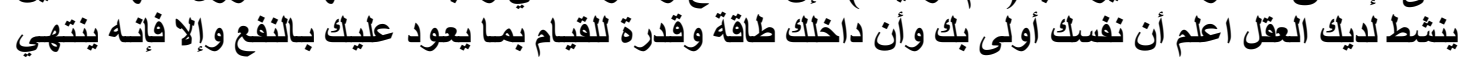




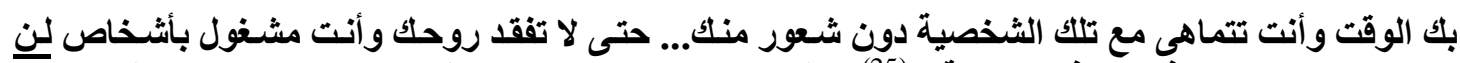

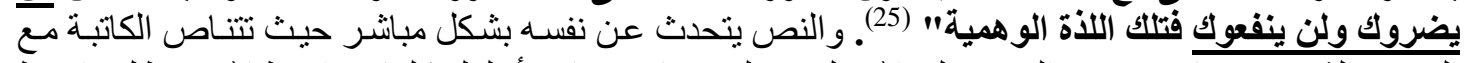

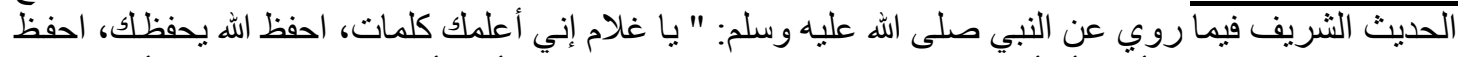

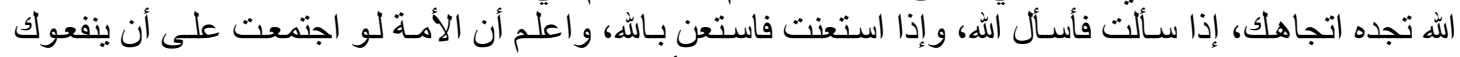

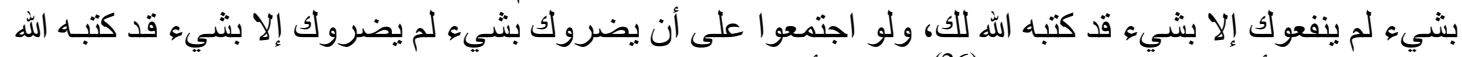

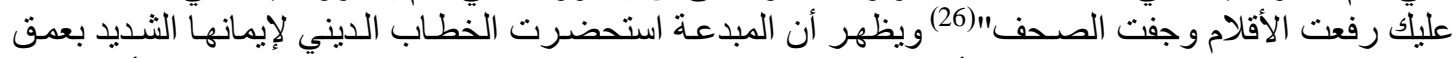

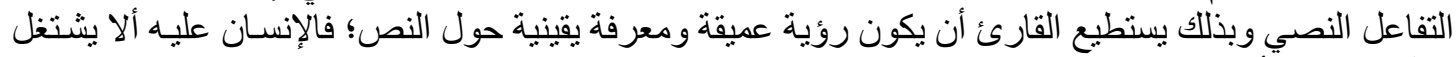

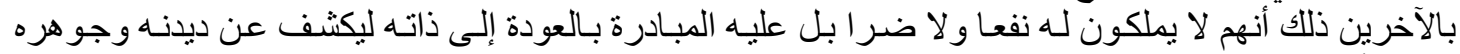

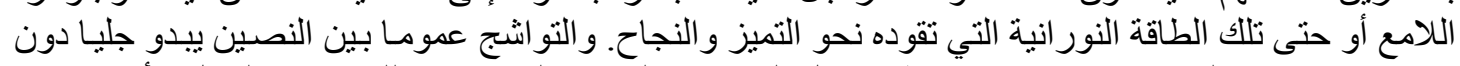

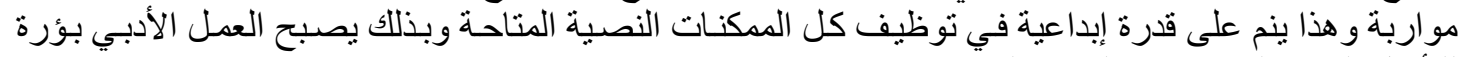
للتأويل الديني المتناغم مع السياق الحاضر.

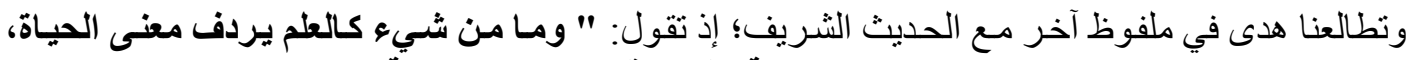

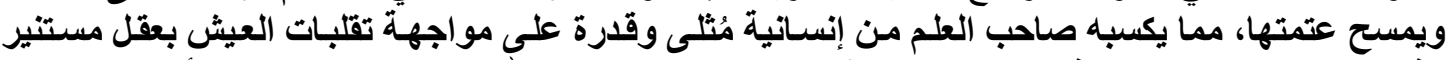

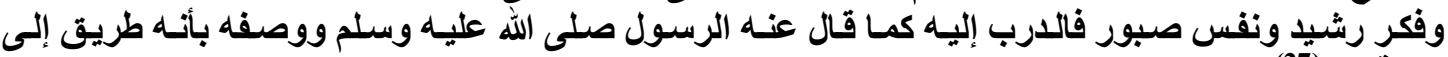

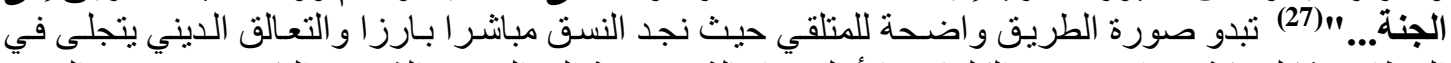

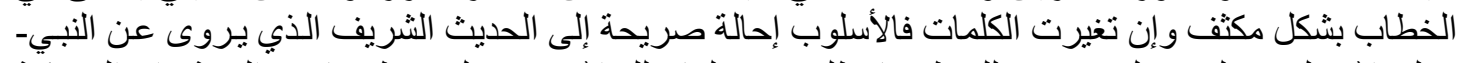

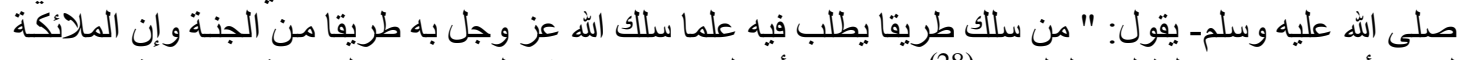

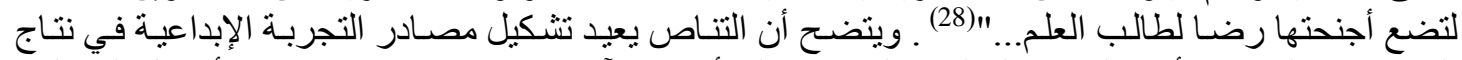

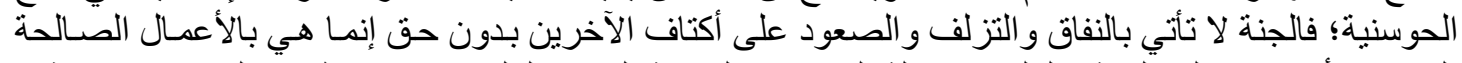

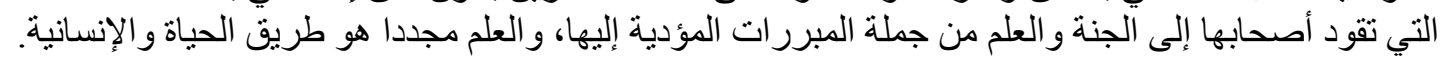

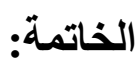

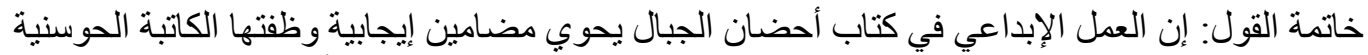

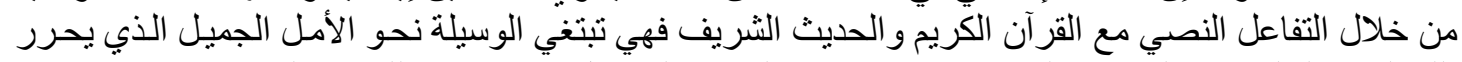

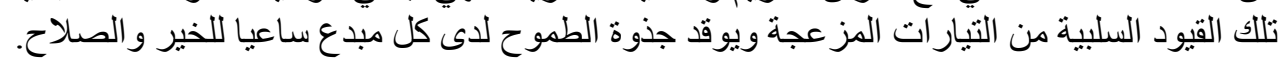

ويتضح أن الكاتبة هدى الحوسني استفادت من كل المعطيات الإيجابية المتاحة، ويأتي التناص في في عملها

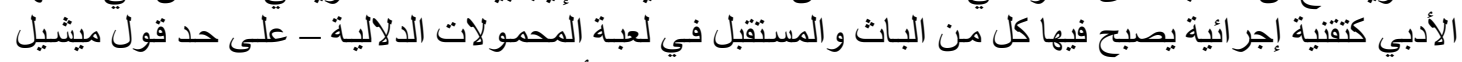

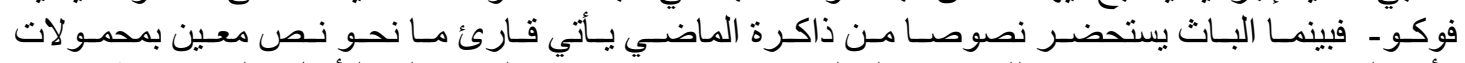

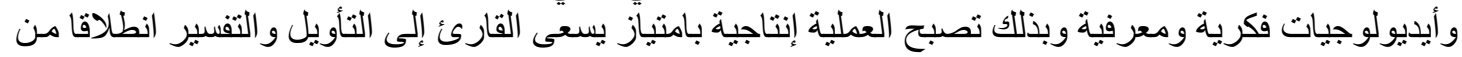

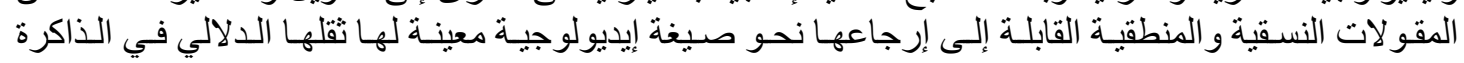

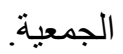

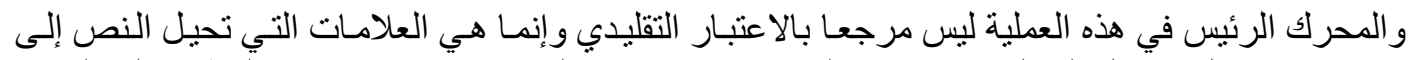

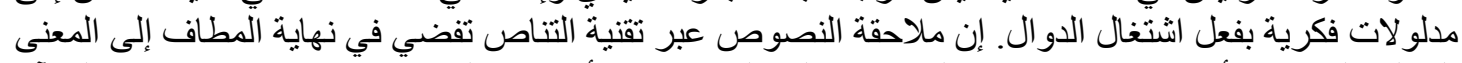

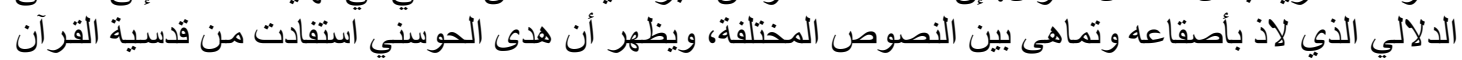

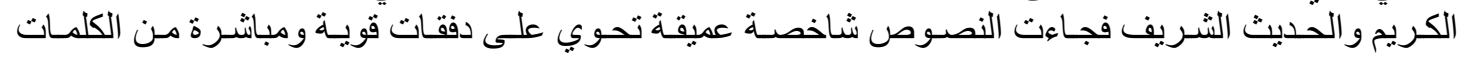

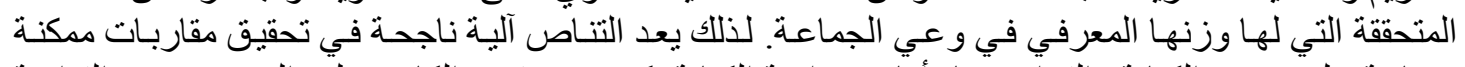

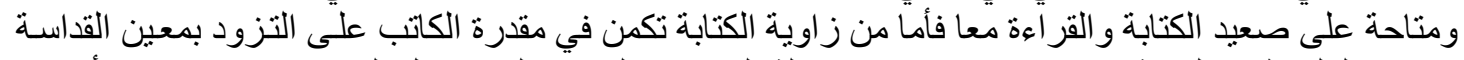

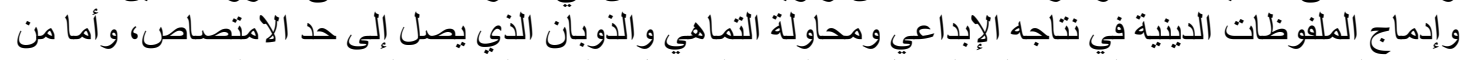

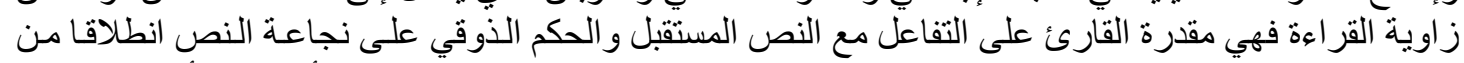

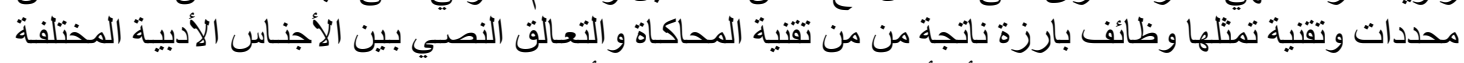

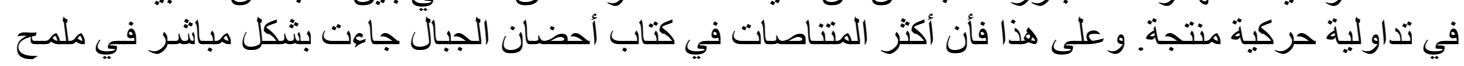




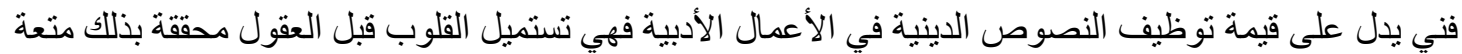

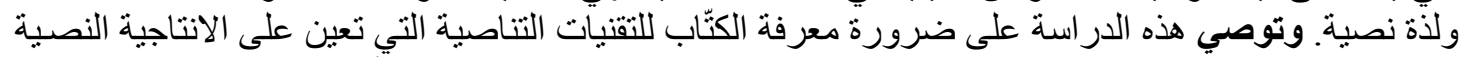

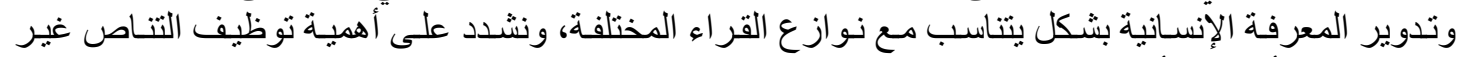

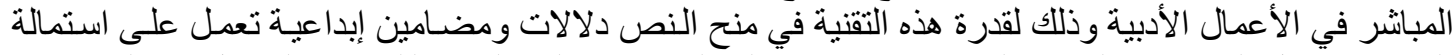

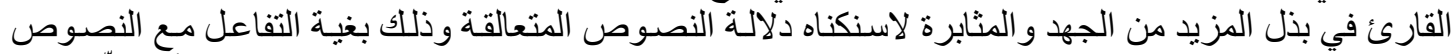

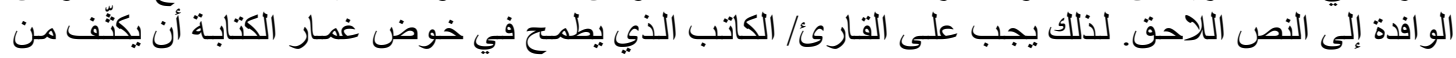

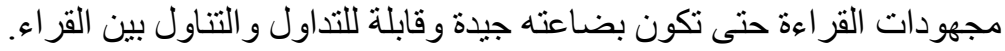

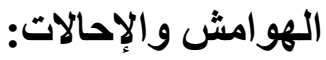

(1) لعور، موسى، التتـاص في روايـة الجازيـة و الدر اويش، ص64، رسـالة ماجستير ، جامعة محمد خيضر، بسكرة،

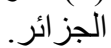

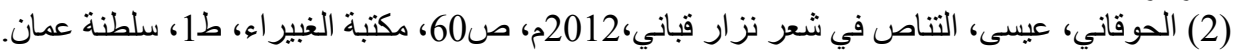

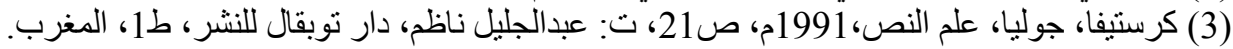

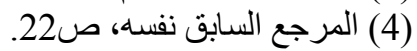

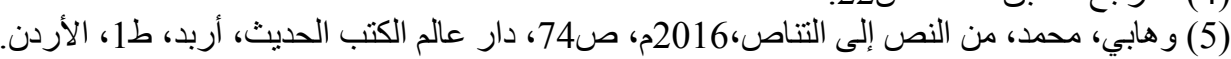

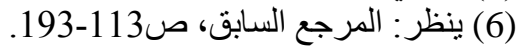

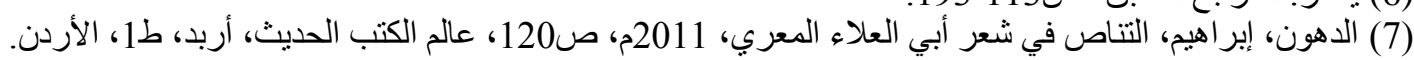

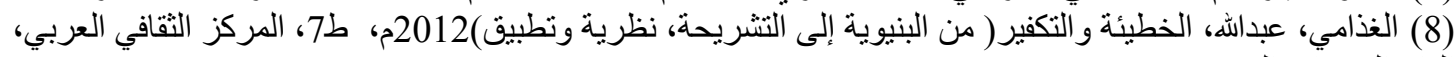

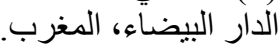

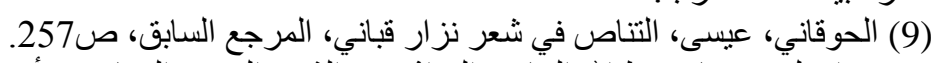

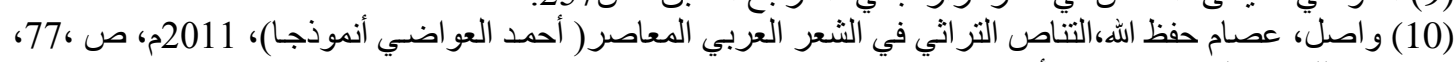
دار غيداء للنشر و التوزيع، طانط، الأردن.

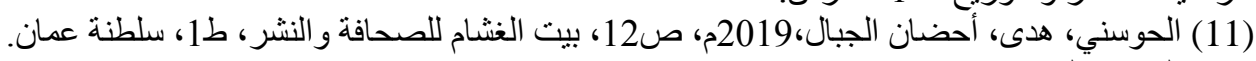

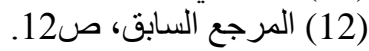

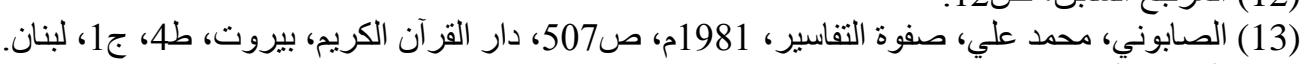

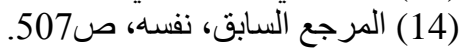

(15) حسنين، نبيل علي، التناص در اسة تطبيقية في شعر شعر اء النقائض( جرير و الفرزدق و الأخطل)، 2010م، ص 58

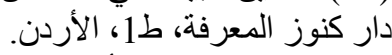

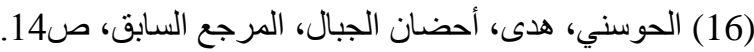

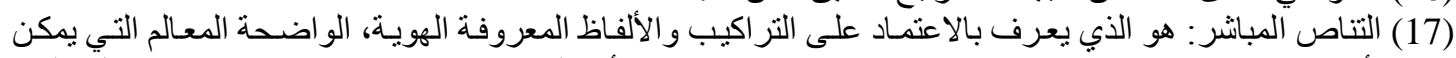

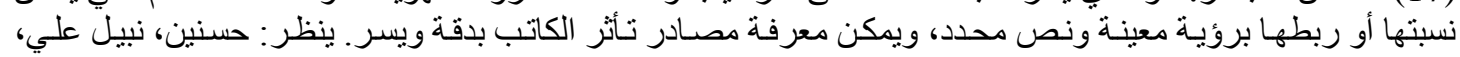

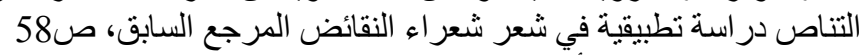

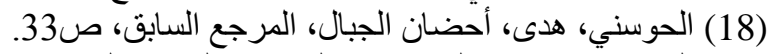

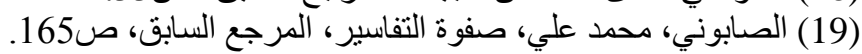

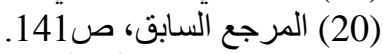

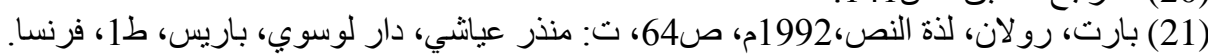

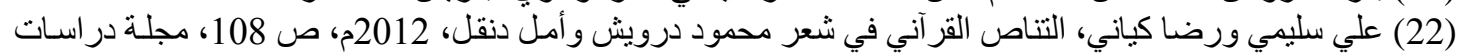

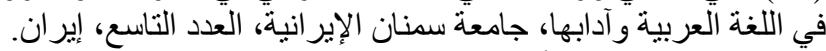

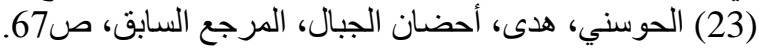

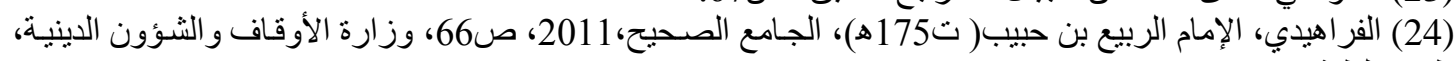
ط1، سلطنة عمان.

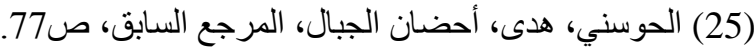

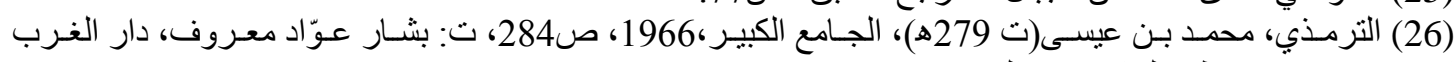

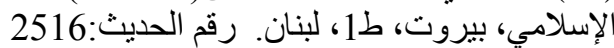

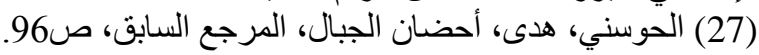




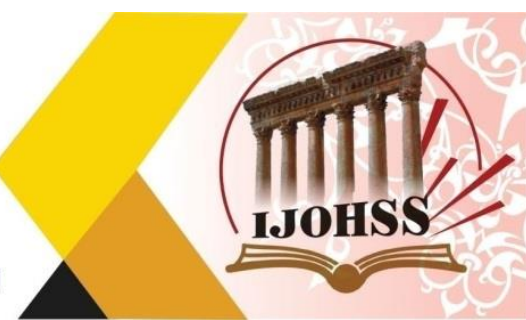

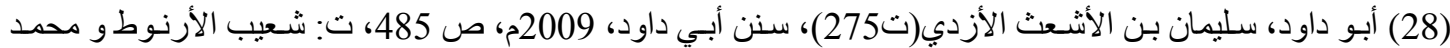
كامل قروبللي، دار الرسالة العالمية، طبعة خاصة، سوريا. باب الحثث على طلب العلم رقم الحديث:3641

المصادر والمراجع: - (المريم

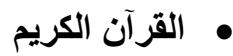
1-أبو داود، سليمان بن الأشعث الأزدي(ت الكريمة 275)، سنن أبي داود، تحقيق: شعيب الأرنوطو محمد كامل قروبللي،

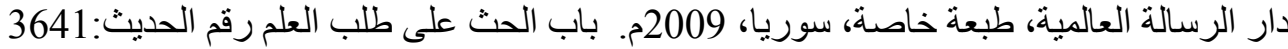

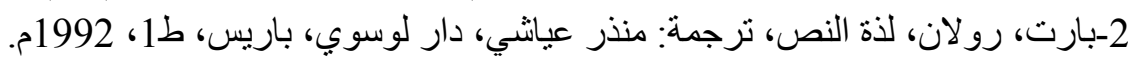
3-الترمذي، محمد بن عيسى(ت 279هـ)، الجامع الكبير ، تحقيق: بشـار عوّ اد معروف، داري، دار الغرب الإسـلامي، بيروت، ط1، 1966. 4-حسنين، نبيل علي، التناص در اسة تطبيقية في شـعر شعر اء النقائض( جرير و الفرزدق و الأخطل)، دار كنوز

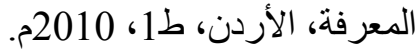

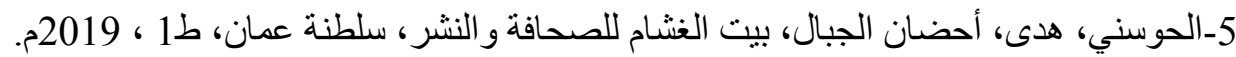

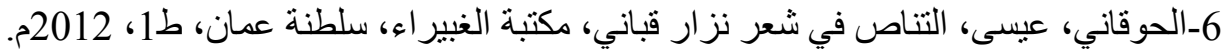

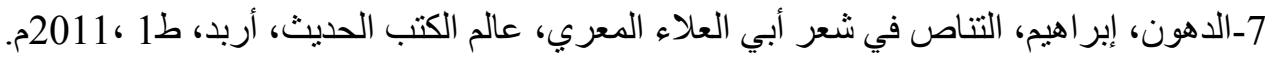

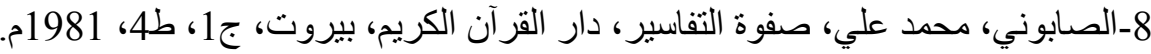

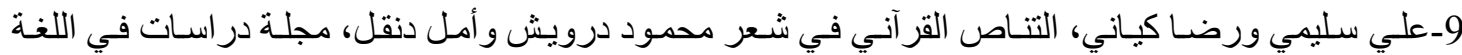
العربية و آدابها، جامعة سمنان الإير انية، العدد التاسع، إيران، إنسان 2012م. 10-الغذامي، عبدالله، الخطيئة والتكفير( من البنيويـة إلى التشريحة، نظرية ونطية ونطبيق)، المركز الثقافي العربي، الدار البيضاء، ط7 ، 2012م. 11-الفر اهيدي، الإمام الربيع بن حبيب( ت175هـ)، الجامع الصحيح ، وزارة الأوقاف و الثُؤون الدينية، سلطنة

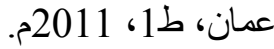

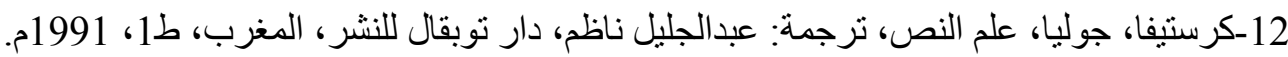

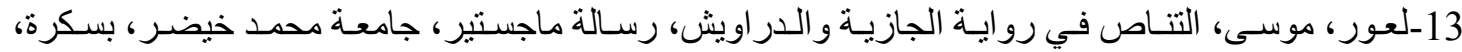

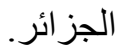
14-و اصل، عصام حفظ الله، التناص التراثي في الثعر العربي المعاصر (أحمد العو اضي أنموذجا)، دار غيداء للنشر و التوزيع، الأردن، ط1 ، 15 ، 2011م. 15-و هابي، محمد، من النص إلى التناص، دار طار عالم الكتب الحديث، أربد، الأردن، ط1 ،2016م . 


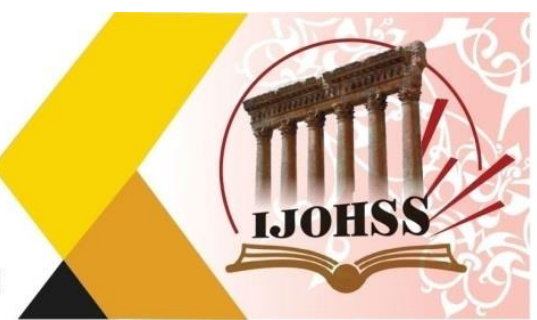

\section{References}

\section{-The Holy Quran}

1- Abu Dawood, Suleiman bin Al-Ash'ath Al-Azdi (d. 275), Sunan Abi Dawood, investigation: Shuaib Al-Arnaut and Muhammad Kamel Qurubli, Dar Al-Resala AlAlameya, special edition, Syria, 2009 AD. Chapter: Urging the Seeking of Knowledge Hadith No.: 3641

2- Barthes, Roland, The Pleasure of the Text, translated by: Munther Ayachi, Lousoy House, Paris, 1, 1992 AD.

3- Al-Tirmidhi, Muhammad bin Issa (died 279 AH), The Great Mosque, investigation: Bashar Awwad Maarouf, Dar al-Gharb al-Islami, Beirut, 1, 1966. Hadith No.: 2516

4- Hassanein, Nabil Ali, Intertextuality: An Applied Study in the Poetry of the Poets of Contradictions (Jarir, Al-Farazdaq and Al-Akhtal), Dar Kunouz Al-Maarifa, Jordan, 1, 2010 AD.

5- Al Hosani, Huda, The Mountains, Beit Al Ghasham for Press and Publishing, Sultanate of Oman, 1st Edition, 2019.

6- Al-Hawqani, Issa, Intertextuality in the Poetry of Nizar Qabbani, Al-Ghubaira Library, Sultanate of Oman, 1, 2012 AD.

7- Fats, Ibrahim, Intertextuality in the Poetry of Abi Al-Ala Al-Maari, Modern Book World, Irbid, 1, 2011 AD.

8- Al-Sabouni, Muhammad Ali, Safwat Al-Tafseer, House of the Noble Qur'an, Beirut, Volume 1, 4th Edition, 1981 AD.

9- Ali Salimi and Reda Kayani, Qur'anic Intertextuality in the Poetry of Mahmoud Darwish and Amal Dunqul, Journal of Studies in Arabic Language and Literature, Semnan University of Iran, issue ninth, Iran, 2012.

10- Al-Ghadami, Abdullah, Sin and Atonement (From Structuralism to Anatomy, Theory and Application), Arab Cultural Center, Casablanca, 7th edition, 2012 AD.

11- Al-Farahidi, Imam Al-Rabi` bin Habib (d. 175 AH), Al-Jami`Al-Sahih, Ministry of Endowments and Religious Affairs, Sultanate of Oman, 1, 2011 AD.

12- Kristeva, Julia, Science of the Text, translated by: Abdel-Jalil Nazim, Dar Toubkal Publishing, Morocco, 1, 1991 AD.

13- Laour, Musa, Intertextuality in the Novel of Jazia and Dervish, Master Thesis, University of Mohamed Khider, Biskra, Algeria.

14- Wasel, Issam Hefdallah, Heritage Intertextuality in Contemporary Arabic Poetry (Ahmed Al-Awadi as a model), Dar Ghaida for Publishing and Distribution, Jordan, 1, 2011 AD.

15- Wahhabi, Muhammad, From Text to Intertextuality, Dar Alam Al-Kutub AlHadith, Irbid, Jordan, 1, 2016 AD. 